\title{
Montreal classification of patient operated for Crohn's disease and identification of surgical recurrence predictors
}

\author{
Caracterização de pacientes operados por doença de Crohn pela \\ classificação de Montreal e identificação de fatores preditores de sua \\ recorrência cirúrgica
}

\author{
Cristiane de Souza Bechara"; Antonio Lacerda Filho, TCBC-MG²; Maria de Lourdes Abreu Ferrari ${ }^{3}$; Déborah Almeida Roquette \\ Andrade ${ }^{4}$; Magda Maria Profeta da Luz ${ }^{2}$; Rodrigo Gomes da Silva ${ }^{2}$
}

A B S T R A C T

\begin{abstract}
Objective: to evaluate Crohn's disease recurrence and its possible predictors in patients undergoing surgical treatment. Methods: We conducted a retrospective study with Crohn's disease (CD) patients undergoing surgical treatment between January 1992 and January 2012, and regularly monitored at the Bowel Clinic of the Hospital das Clínicas of the UFMG. Results: we evaluated 125 patients, $50.4 \%$ female, with a mean age of 46.12 years, the majority $(63.2 \%)$ diagnosed between 17 and 40 years of age. The ileum was involved in 58.4\%, whereas stenotic behavior was observed in $44.8 \%$, and penetrating, in $45.6 \%$. We observed perianal disease in $26.4 \%$ of cases. The follow-up average was 152.40 months. Surgical relapse occurred in $29.6 \%$, with a median time of 68 months from the first operation. Conclusion: The ileocolic location, penetrating behavior and perianal involvement (L3B3p) were associated with increased risk of surgical recurrence.
\end{abstract}

Key words: Crohn's Disease. Classification. Recurrence. Risk factors

\section{INTRODUCTION}

C rohn's disease (CD) is a chronic transmural inflammatory disease that can affect any segment of the digestive tract associated with intestinal manifestations and other immunological alterations. Its clinical presentation depends on the location and include diarrhea, abdominal pain, weight loss, fever, mucorreia or hematochezia. Clinical behavior comprises alternating periods of exacerbation and remission. The typical presentation is the involvement of discontinuous segments of the gastrointestinal tract. The inflammatory process can lead to the development of complications such as stenosis, abscesses and fistulas ${ }^{1}$.

Among the many classifications proposed for $C D$, the Montreal2, introduced in 2005, is the most used and aims to standardize the characterization of the disease, using reproducible clinical and epidemiological characteristics. Such categorization is desirable so that one can correlate particular disease phenotypes with possible clinical outcomes and prognosis, to select the best therapeutic strategy and the most appropriate follow-up for each patient.

Despite the increasing success with the clinical treatment of $C D$, about $75 \%$ of patients require surgical intervention within 20 years of onset. Surgery, however, is not curative, postoperative recurrence being common ${ }^{3}$. This recurrence may be defined as clinical, endoscopic, histological, radiological or surgical. Often the disease is asymptomatic until the intestinal inflammation is severe, corresponding to the development of complications requiring a new operation ${ }^{4}$. Little is known specifically on surgical recurrence, there being few studies published in this respect.

The aim of this study was to characterize a cohort of patients with Crohn's disease treated at a tertiary referral center for intestinal inflammatory diseases, based on the Montreal classification, and to evaluate surgical recurrence and its possible predictors.

\section{METHODS}

We retrospectively analyzed data from 137 patients diagnosed with Crohn's disease (CD) who were followed-up at the Bowel Intestine Clinic of the Hospital das Clínicas, UFMG, and underwent surgical treatment between January 1992 and January 2012. Twelve were excluded due to loss of essential data for the preparation of the study, 125 patients operated remaining for evaluation.

1. Coloproctology Service, Clinics Hospital, Federal Universityof Minas gerais - UFMG, Belo Horizonte, Minas Gerais State - MG, Brazil; 2. Department of the Surgery, Faculty of Medicine, UFMG; 3. Department of Internal Medicine, Faculty of Medicine, UFMG; 4. Facultyof Medicine, UFMG. 
Data were collected from medical records and recorded in a specific protocol.

This study was approved by the Ethics in Research Committee of the Universidade Federal de Minas Gerais (CEP-UFMG - opinion ETIC 0156.0.203.000-11).

The variables studied were age, gender, clinical presentation according to the Montreal classification, time of disease evolution, smoking (smoking at diagnosis, regardless of the number of cigarettes smoked and the habit interruption after treatment start), clinical treatment performed before the first operation, progression of the disease until operation, surgical indication, type of surgery, postoperative complications, medications for maintenance of remission after operation, surgical recurrence, number of operations, type of new operation and date of performance.

Patients for whom the diagnosis of CD was perioperatively established, without previous medical treatment, were considered as receiving urgent surgical treatment.

\section{Montreal classification}

This classification subdivides CD according to three main phenotypic characteristics: age at diagnosis (A), topographic location (L) and clinical behavior $(\mathrm{B})^{2}$.

The age parameter takes account of the time when the diagnosis was definitely established. There are three possibilities: $f 16$ years (A1); between 17 and 40 years $(\mathrm{A} 2)$; and $>40$ years $(\mathrm{A} 3)^{2}$.

Location is defined as the point of maximum anatomical extent of the disease at any time. There are four possibilities: the terminal ileum (L1, disease limited to the lower third of the small intestine, with or without the involvement of the cecum); colon (L2, anywhere between the cecum and the rectum, without involvement of the upper digestive tract); ileocolic ( $\mathrm{L} 3$, terminal ileum disease and anywhere between the ascending colon and the rectum); and the upper gastrointestinal tract ( $L 4$, any location proximal to the terminal ileum, except the mouth). If there is concomitant proximal (L4) and distal (L1 to L3) involvement, the L4 category should be added as a modifier; if the distal condition is not found, $L 4$ remains exclusively considered. This creates seven location possibilities: L1, L2, $\mathrm{L} 3, \mathrm{~L} 4, \mathrm{~L} 4+\mathrm{L} 1, \mathrm{~L} 2+\mathrm{L} 4$ and $\mathrm{L} 3+\mathrm{L}^{2}$.

Clinical behavior is classified as non-stenotic and non-penetrating (B1), stenosing (B2) and penetrating (B3). Non-penetrating, non-stenotic disease is defined as the presence of inflammation, without evidence of stenosis, or fistula. Stenotic disease is defined by the occurrence of luminal narrowing. Penetrating disease is defined by the occurrence of abdominal fistulas or inflammatory masses and / or abscess in any period of the disease. When there is perianal disease, this should be separately indicated by a marker ( $p$ ), which must be added to the categories B1, B2 and B3. Thus, there are six possibilities: B1, B2, B3, B1p, $B 2 p$ and $B 3 p^{2}$.

\section{Statistical analysis}

Data descriptions were based on frequency tables and graphs. For quantitative variables, we computed the average and standard deviation when they presented normal distribution, and median (interquartile range) when the distribution was not normal, after application of the ShapiroWilk test.

Initially we analyzed the association between the study variables and the number of operations (1 and e" 2) and subsequently we evaluated the association of the variables with the type of operation (elective and emergency) through the asymptotic or accurate Pearson chi-square tests. For the analysis of quantitative variables we used the Student $t$ or Mann-Whitney tests, depending on the distribution' the normality or not. The level of significance was $5 \%(p<0.05)$.

We performed the multivariate analysis of the association between the number of operations and the study variables by the logistic regression model adjustment. The model was adequate when the $p$ value was less than 0.05 .

\section{RESULTS}

There were similar gender distribution, with a slight predominance of females (63 patients - 50.4\%) and the mean age was $46.12 \pm 12.2$ years. Forty-eight patients were smokers (38.4\%).

Six patients (4.8\%) were diagnosed younger than age $16(\mathrm{~A} 1), 79(63.2 \%)$ between 17 and 40 years (A2) and $40(32 \%)$, over $40(\mathrm{~A} 3)$.

In 73 (58.4\%) patients the terminal ileum was affected (L1); in 22 (17.6\%), the colon (L2) and 29 (23.2\%) had ileocolic disease (L3). The upper gastrointestinal tract (L4) was committed in six patients, one in isolation $(0.8 \%)$, four (3.2\%) in association with involvement of the terminal ileum $(L 1+L 4)$ and in one patient $(0.8 \%)$, in combination with ileocolic involvement $(\mathrm{L} 1+\mathrm{L} 3)$.

Twelve patients (9.6\%) had non-stenotic / nonpenetrating disease (B1); 56 (44.8\%) stenotic disease (B2) and 57 (45.6\%) had penetrating disease (B3); 33 patients (26.4\%) had associated perianal disease: five (4\%) nonstenotic and non-penetrating (B1P), five (4\%) stenotic (B2P) and 23 (18.4\%) penetrating (B3p).

Fifty-four patients (43.2\%) received preoperative clinical treatment (Table 1), the association of another type of medicine being common. Seventy-one (56.8\%) patients underwent surgical treatment, usually of urgency, without prior medical treatment nor confirmed diagnosis.

The mean follow-up of patients was 152.4 months. The first surgery was performed on average 29 months after diagnosis. The most frequent surgical indications were acute inflammatory abdomen and ileal obstruction (Table 2).

The main surgical decisions during the first operation were ileocolectomy in 49 (39.2\%) patients and 
bowel resection in 46 (36.8\%). The laparoscopic approach was applied in three patients. Anoperineal interventions were performed in 17 patients: simple fistulotomy, abscess drainage, placement of seton and excision of plicomas were the most common procedures (Figure 1).

Postoperative medication was used in 98 patients (78.4\%), some patients receiving more than one drug; azathioprine was used in 61 (48.8\%), mesalazine in 27 $(21.6 \%)$, sulfasalazine in $25(20 \%)$, infliximab in 16 $(12.8 \%)$, methotrexate in two patients $(1.6 \%)$ and adalimumab in one (0.8\%) (Table 3 ).

Postoperative complications occurred in 23 patients (18.4\%). Anastomotic leaks occurred in 15 individuals $(12 \%)$, superficial surgical site infection in six $(4.8 \%)$, pneumonia in one patient $(0.8 \%)$ and deep vein thrombosis in one $(0.8 \%)$, which evolved to death due to pulmonary thromboembolism.

Surgical recurrence occurred in 37 patients (29.6\%), on average 68 months after the first intervention, ranging from three to 204 months. In 27 patients (57.5\%) recurrence ensued in the pre-anastomotic region, and in 20 patients $(42.5 \%)$ it occurred in other places: proximal small intestine in nine $(7.2 \%)$, terminal ileum in five $(4 \%)$, perianal region in five patients (4\%), colon in one $(0.8 \%)$ and rectum in one patient $(0.8 \%)$. Patients with symptoms recurrence required two or more operations. Fourteen patients (11.2\%) underwent three operations, the second recurrence happening, on average, 47 months after the first. Four patients (3.2\%) required four operations, 72 months being the average time of the third recurrence (Figure 2).

The ileocolic location (L3), the penetrating behavior (B3) and presence of perianal disease (B3p), as well as the time of disease progression, were significantly associated with surgical recurrence (Tables 3 and 4).

When the emergency operations were compared with the elective ones, we observed that there was no difference in relation to surgical recurrence. Regarding the Montreal classification, we observed that patients younger than age 16 and aged between 17 and 40 years at diagnosis underwent elective surgery more often. On the other hand, patients aged over 40 years underwent emergency surgery more frequently (Table 5).

Also regarding the type of operation, the main indication for surgery in the group undergoing emergency procedures was inflammatory acute abdomen in 30 patients $(42.9 \%)$, followed by intestinal obstruction in 27 (38.6\%). In the group of patients undergoing elective operations, the main indication was intestinal obstruction in 17 patients $(30.9 \%)$, followed by perianal sepsis in $11(20 \%)$ and clinical intractability in ten (18.2\%) (Table 5).

\section{DISCUSSION}

The Montreal classification has been increasingly used in patients with Crohn's disease (CD) due to its
Table 1 - $\quad$ Preoperative clinical treatment $(n=54)$.

\begin{tabular}{lr}
\hline Previous Drug & $\mathrm{n}(\%)$ \\
\hline Sulfasalazine & $25(20)$ \\
Mesalazine & $14(11.2)$ \\
Corticosteroids & $42(33.6)$ \\
Azathioprine & $27(21.6)$ \\
Mercatopurina & $1(0.8)$ \\
Methotrexate & $5(4)$ \\
Infliximab & $6(4.8)$ \\
\hline
\end{tabular}

Table 2 - Main surgical indications $(n=125)$.

\begin{tabular}{lrr}
\hline Indication & \multicolumn{2}{c}{$\mathbf{n}(\%)$} \\
\hline Acute Abdomen & 36 & $(28.8)$ \\
Ileal Obstruction & 35 & $(28)$ \\
Perianal Disease & 17 & $(13.6)$ \\
Ileal Perforation & 10 & $(8)$ \\
Clinical Intractability & 10 & $(8)$ \\
Jejunal Obstruction & 8 & $(6.4)$ \\
Enterocutaneous Fistula & 4 & $(3.2)$ \\
Enterovesical Fistula & 3 & $(2.4)$ \\
Enteroenteric Fistula & 2 & $(1.6)$ \\
Colonic Perforation & 2 & $(1.6)$ \\
Colonic Obstruction & 1 & $(0.8)$ \\
Enterouterine Fistula & 1 & $(0.8)$ \\
Refractory Bleeding & 1 & $(0.8)$
\end{tabular}

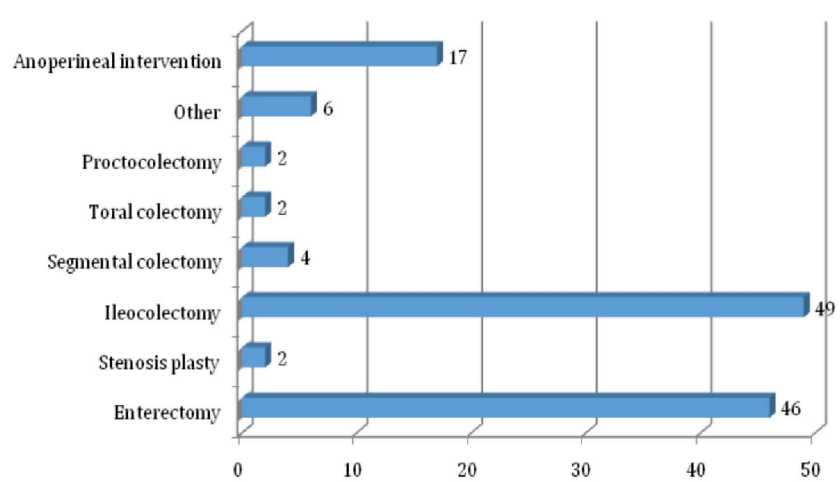

Figure 1 - Conduct adopted in the first operation ( $n=125)$.

diagnostic and therapeutic implications. However, despite its great utility, it is still little used in Brazil, especially when it comes to evaluating potential predictors of recurrence in a population of surgical patients. Its use in a cohort of patients with CD treated surgically, evaluated and monitored on a university reference center for treatment of inflammatory bowel disease can contribute to a greater understanding of the disease presentation and its response 
Table 3 - $\quad$ Analysis of association between the number of operations in patients with Crohn's disease and the study variables (n $=125$ )

\begin{tabular}{|c|c|c|c|c|c|c|c|}
\hline \multirow[b]{2}{*}{ Variables n (\%) } & \multicolumn{6}{|c|}{ Number of Surgeries } & \multirow[b]{2}{*}{$p$-value } \\
\hline & \multicolumn{2}{|c|}{$\begin{array}{c}1 \\
\mathrm{n}=88\end{array}$} & \multicolumn{2}{|c|}{$\begin{array}{ll} & >2 \\
\mathrm{n}=37 & (29,6 \%)\end{array}$} & \multicolumn{2}{|c|}{$\begin{array}{c}\text { Total } \\
n=125\end{array}$} & \\
\hline \multicolumn{8}{|l|}{ Age of diagnosis } \\
\hline A1 & 3 & (3.4) & 3 & $(8.1)$ & 6 & $(4.8)$ & 0.319 \\
\hline A2 & 59 & $(67.0)$ & 20 & $(50.1)$ & 79 & $(63.2)$ & \\
\hline A3 & 26 & $(29.5)$ & 14 & (37.8) & 40 & $(32.0)$ & \\
\hline \multicolumn{8}{|l|}{ Location } \\
\hline L1 & 57 & $(64.8)$ & 16 & $(43.2)$ & 73 & $(58.4)$ & 0.039 \\
\hline L2 & 15 & $(17.0)$ & 7 & (18.9) & 22 & $(17.6)$ & \\
\hline L3 & 16 & $(18.2)$ & 13 & (35.1) & 29 & $(23.2)$ & \\
\hline L4 & 0 & & 1 & $(2.7)$ & 1 & $(0.8)$ & \\
\hline \multicolumn{8}{|l|}{ Behavior } \\
\hline B1 & 8 & $(9.1)$ & 4 & $(10.8)$ & 12 & $(9.6)$ & 0.001 \\
\hline B2 & 49 & $(55.7)$ & 7 & (18.9) & 12 & $(9.6)$ & \\
\hline B3 & 31 & $(35.2)$ & 26 & (70.3) & 57 & $(45.6)$ & \\
\hline \multicolumn{8}{|l|}{ Perianal Disease } \\
\hline B1p & 4 & $(4.5)$ & 1 & $(2.7)$ & 5 & $(4.0)$ & 0.033 \\
\hline B2p & 5 & $(5.7)$ & 0 & & 5 & $(4.0)$ & \\
\hline B3p & 11 & $(12.5)$ & 12 & (32.4) & 23 & $(18.4)$ & \\
\hline \multicolumn{8}{|l|}{ Smoking } \\
\hline Yes & 33 & $(37.5)$ & 15 & $(40.5)$ & 48 & $(38.4)$ & 0.319 \\
\hline No & 55 & $(62.5)$ & 22 & (59.5) & 40 & $(32.0)$ & \\
\hline \multicolumn{8}{|c|}{ Previous medication } \\
\hline Sulfasalazine & 17 & $(19.3)$ & 8 & $(21.6)$ & 25 & (20) & 0.769 \\
\hline Mesalamine & 13 & $(14.8)$ & 1 & $(2.7)$ & 14 & $(11.2)$ & 0.063 \\
\hline Corticoids & 32 & $(36.4)$ & 10 & $(27.0)$ & 42 & (33.6) & 0.313 \\
\hline Azathioprine & 23 & $(26.1)$ & 4 & (10.8) & 27 & $(21.6)$ & 0.057 \\
\hline Mercaptopurine & 1 & $(1.1)$ & 0 & & 1 & $(0.8)$ & 1.000 \\
\hline Methotrexate & 5 & $(5.7)$ & 0 & & 1 & (0.8) & 0.320 \\
\hline Infliximab & 6 & (6.8) & 0 & & 6 & (4.8) & 0.178 \\
\hline \multicolumn{8}{|c|}{ Postoperative medication } \\
\hline Azathioprine & 43 & $(48.9)$ & 18 & $(48.6)$ & 61 & $(48.8)$ & 0.982 \\
\hline Infliximab & 12 & (13.6) & 4 & (10.8) & 16 & (12.8) & 0.776 \\
\hline Other & 44 & $(50.0)$ & 15 & (40.5) & 50 & $(47.2)$ & 0.334 \\
\hline
\end{tabular}

to operative treatment. In the Brazilian literature, only a single study aimed to assess the factors of CD surgical recurrence ${ }^{5}$. In that study, Albuquerque et al. observed that penetrating clinical presentation and the presence of intestinal perforation are predictors of recurrence in surgical patients ${ }^{5}$. However, that article does not apply the Montreal classification and its prognostic implications.

Moreover, one may wonder whether CD would not be less frequently suspected in patients over 40 years of age, since inflammatory bowel diseases are considered to traditionally affect younger patients.

It is of paramount importance to study the concurrent involvement of the upper gastrointestinal and other locations, a fact that was not contemplated by other classifications, with possible underestimation of the disease incidence in such topography. In this study, the involvement of the upper gastrointestinal (GIT) tract occurred in six patients (4.8\%), 4\% concurrent to other locations. This data are similar to the published by Thin et al., in that only $1 \%$ of the study population had an isolated upper GIT condition and 3.3\% had concomitant involvement, L1, L2 or L37. It has also been reported that the risk of recurrence is higher when the disease occurs in the terminal ileum and ileocolic regions ${ }^{8.9}$. In this cohort, patients with L3 location had higher surgical recurrence, which had already been confirmed by other authors ${ }^{3}$ 


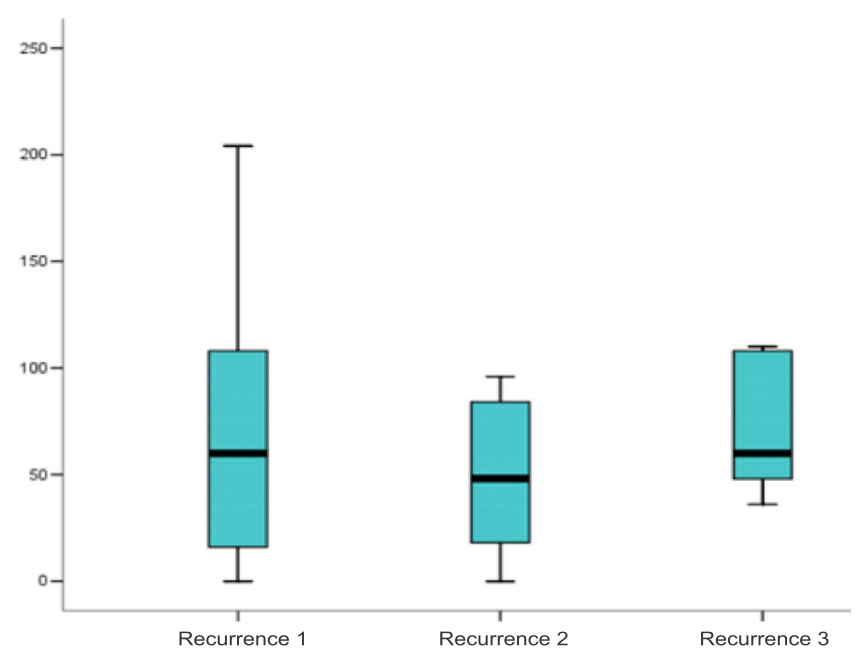

Figure 2 - Surgical recurrence time in patients operated for Crohn's disease $(n=37)$.

It is well established that the penetrating behavioral features more aggressive clinical course and more recurrence index ${ }^{4}$, as well as the presence of perianal disease, often associated with colonic disease, which has also been considered an important marker of severe disease $^{10}$. In this study, it was observed that B3 behavior patients had more surgical recurrence, which confirms the higher aggressiveness of this kind of CD behavior. However, despite the perianal disease is more associated with $C D$ penetrating form, even grouped together with this form in the old Vienna classification ${ }^{11}$, enteric fistula does not occur in up to $80 \%$ of patients with perianal disease ${ }^{2}$, which is probably relatedto the genetic profile of the disease.

With regard to surgical treatment, ileocolectomy and enterectomy were the most common procedures, which conforms to the CD topographical location in the study population (L1 in $58.4 \%$ of patients). In this cohort, few patients underwent plasty of stenosis, always Heine-type Mickulicz, in segmental stenoses ${ }^{12}$. This is because most stenoses were long, resulting in the realization of enterectomies or the need for more extensive plasties, type Jaboulay or Michelassi ${ }^{12}$, which are not used in our service. Moreover, as most of the patients underwent emergency surgery, resection allowed the confirmation of CD by histological analysis of the specimen in patients without prior diagnosis.

In this cohort, $12 \%$ of patients had anastomotic leak and $4.8 \%$ had superficial surgical site infection. These complication rates are high, since the reports of septic abdominal complication rates in the postoperative period of intestinal resection for CD range from $8 \%$ to $16 \%$. These rates are higher than those recorded in patients undergoing bowel resection by other benign diseases ${ }^{13}$. It must be pointed out that this study was conducted in a reference center, at a hospital in tertiary complexity and therefore many of the operated patients are severely ill, with compromised nutritional status and in use of medications that lead to anastomotic dehiscence risk.

The obtained surgical recurrence rate of $29.6 \%$, with a mean 68-month time onset, corresponding to 5.6 years, is consistent with the rates reported in the literature, which vary according to the definition of recurrence used: endoscopic, surgical or clinical ${ }^{14}$. Patients undergoing endoscopic ileocolectomy present relapse in $90 \%$ of cases in the absence of treatment, while clinical recurrence reaches $20-25 \%$ per year ${ }^{15}$. In what concerns surgical recurrence, reoperation rates range from, 11 to $32 \%$ in five years, $20-44 \%$ in ten and 46 to $65 \%$ in 20 years ${ }^{16}$.

Among the Montreal classification features, the factors most related to surgical recurrence in this study were the ileocolic location (L3) and the penetrating behavior (B3). In the national literature, in a paper published by Albuquerque et al., who also evaluated postoperative recurrence, penetrating behavior was also associated with higher recurrence rates ${ }^{5}$.

We also observed that the duration of the disease was more associated with recurrence, which conforms to CD's natural history, a chronic, progressive and almost invariably evolving into complications that culminate with surgical treatment. The long follow-up of this cohort in a university academic ambulatory-care character, averaging 152.4 months, accounting for more than 12 years, makes possible the proper assessment of a chronic disease with high morbidity but relative low mortality.

As for the analysis of other surgical recurrence predictors, smoking is widely deemed a negative prognostic factor, being recognized both as a risk factor for the onset

Table 4 - Multivariate analysis between the number of operations, the time of evolution and disease behavior.

\begin{tabular}{|c|c|c|c|c|c|c|c|c|}
\hline \multirow[b]{2}{*}{ Variables } & \multicolumn{5}{|c|}{ Amount of operations } & \multirow[b]{2}{*}{ OR } & \multirow[b]{2}{*}{ IC95\% OR } & \multirow[b]{2}{*}{$p$-value } \\
\hline & $\mathrm{N}=$ & 88 & $\begin{array}{r}> \\
\mathrm{n}=\end{array}$ & & $\begin{array}{l}\text { Total } \\
n=125\end{array}$ & & & \\
\hline $\begin{array}{l}\text { Time evolution } \\
\text { Behavior }\end{array}$ & $133.8 \pm$ & 97.2 & 179.4 & 81.1 & $147.3 \pm 94.8$ & 1.01 & $1.00 ; 1.01$ & 0.031 \\
\hline B1 & 8 & $(66.7)$ & 4 & (33.3) & 12 & 1 & & \\
\hline B2 & 49 & (87.5) & 7 & (12.5) & 56 & 0.10 & $0.02 ; 0.54$ & 0.686 \\
\hline B3 & 31 & (54.4) & 26 & $(45.6)$ & 57 & 1.34 & $0.33 ; 5.48$ & 0.007 \\
\hline
\end{tabular}


Table 5 - Association between the type of operation (elective or emergency) in patients with Crohn's disease and the study variables $(n=125)$.

\begin{tabular}{|c|c|c|c|c|c|c|c|}
\hline \multirow[b]{2}{*}{ Variables } & \multicolumn{6}{|c|}{ Types of surgery } & \multirow[b]{2}{*}{$p$-value } \\
\hline & Urgenc & cy $(n=70)$ & Electi & e $(n=55)$ & Total & $(n=125)$ & \\
\hline \multicolumn{8}{|l|}{ Number of surgeries } \\
\hline 1 & 46 & $(65.7)$ & 42 & (76.4) & 88 & $(70.4)$ & 0.195 \\
\hline$>2$ & 24 & (34.3) & 13 & $(23.6)$ & 37 & (29.6) & \\
\hline \multicolumn{8}{|l|}{ Age at diagnosis } \\
\hline A1 & 1 & (1.4) & 5 & $(9.1)$ & 6 & $(4.8)$ & 0.04 \\
\hline $\mathrm{A} 2$ & 42 & (60) & 37 & (67.3) & 79 & $(63.2)$ & \\
\hline A3 & 27 & (38.6) & 13 & $(23.6)$ & 40 & (32) & \\
\hline \multicolumn{8}{|l|}{ Location } \\
\hline $\mathrm{L} 1$ & 43 & (61.4) & 30 & $(54.5)$ & 73 & $(58.4)$ & 0.084 \\
\hline L2 & 8 & $(11.4)$ & 14 & (25.5) & 22 & $(17.6)$ & \\
\hline L3 & 19 & $(27.1)$ & 10 & $(18.2)$ & 29 & $(23.2)$ & \\
\hline Ł4 & 0 & (0) & 1 & $(1.8)$ & 1 & $(0.8)$ & \\
\hline \multicolumn{8}{|l|}{ Behavior } \\
\hline B1 & 6 & (8.6) & 6 & $(10.9)$ & 12 & (9.6) & 0.902 \\
\hline B2 & 32 & $(45.7)$ & 24 & $(46.3)$ & 56 & $(44.8)$ & \\
\hline B3 & 32 & $(45.7)$ & 25 & $(45.5)$ & 57 & $(45.6)$ & \\
\hline \multicolumn{8}{|l|}{ Surgical Indication } \\
\hline Inflammatory acute abdomen & 30 & $(40.2)$ & 6 & $(10.9)$ & 36 & $(28.8)$ & $<0.0001$ \\
\hline Jejunal Obstruction & 4 & $(5.7)$ & 4 & (7.3) & 8 & $(6.4)$ & 1.000 \\
\hline Ileal obstruction & 23 & $(32.9)$ & 12 & $(21.8)$ & 35 & $(28.0)$ & 0.172 \\
\hline Colonic pseudo-obstruction & 0 & (0) & 1 & $(1.8)$ & 1 & $(0.8)$ & 0.440 \\
\hline Refractory bleeding & 1 & $(1.4)$ & 0 & (0) & 1 & $(0.8)$ & 1.000 \\
\hline Enterocutaneous fistula & 1 & (1.4) & 3 & (5.5) & 4 & (3.2) & 0.319 \\
\hline Enteroenteric fistula & 0 & (0) & 2 & (3.6) & 2 & (1.6) & 0.192 \\
\hline Enterovesical fistula & 1 & $(1.4)$ & 2 & (3.6) & 2 & (2.4) & 0.582 \\
\hline Enterouterine fistula & 0 & (0) & 1 & (1.8) & 1 & (0.8) & 0.331 \\
\hline lleal perforation & 7 & $(10.0)$ & 3 & (5.5) & 10 & (8.0) & 0.510 \\
\hline Colon perforation & 0 & (0) & 2 & (3.6) & 2 & (1.6) & 0.192 \\
\hline Clinical intractability & 0 & (0) & 10 & $(18.2)$ & 10 & (8.0) & $<0.0001$ \\
\hline Perianal sepsis & 6 & (8.6) & 11 & $(20.0)$ & 17 & $(13.6)$ & 0.064 \\
\hline
\end{tabular}

of the disease, and for recurrence after surgical treatment ${ }^{3.5}$. Nonetheless, this was not confirmed in this study (Table 4).

We did not aim to evaluate clinical treatment, nor the association between the type of drug treatment with the need for surgical treatment. It is noteworthy that in this study most patients (56.4\%) underwent surgical treatment without previous clinical treatment, ie, had suspected and confirmed diagnosis peri- and postoperatively. Importantly, patients belong to a reference clinic, which often receives individuals who were operated in various other services, often undiagnosed. One cannot say whether these patients had a more acute disease course or stopped seeking medical assistance at the start of symptoms, losing the opportunity to establish the diagnosis without the need for surgical intervention. Many may have been treated in emergency rooms, where the initial condition of acute inflammation of the ileocecal region was interpreted as inflammatory acute abdomen, with strong suspicion of acute appendicitis.

The relationship between appendicitis, appendectomy and Crohn's disease is not well established. Many patients who present with acute ileitis can be submitted to appendectomy for suspected acute appendicitis, when the true diagnosis is Crohn's disease, which can be diagnosed in the perioperative period or a few months later. However, it is not yet confirmed if appendectomy is a risk factor for CD or previous appendectomy changes the natural history of the $C D^{17}$.

We did not to evaluate postoperative prophylactic medication, as many of these patients were operated on other services, sometimes staying long periods without any medication, being referred only when they became symptomatic again. In any case, there was no relationship between preoperative clinical treatment and greater surgical 
recurrence rate, nor regarding the use of prophylactic postoperative medication (Table 4).

In a study published by Latellaet al. ${ }^{18}$, who evaluated CD's clinical course in patients undergoing surgical treatment for acute abdomen and had their diagnosis revealed at surgery, and observed that the risk of these patients being submitted to reintervention due to surgical recurrence was lower. The authors also found that patients with involvement of the terminal ileum and penetrating or stenotic behavior were at greater risk of being subjected to exploratory laparotomy without prior diagnosis. In another study ${ }^{19}$, in which they compared two groups who underwent early surgery (without medical treatment) and late surgery (along the course of the disease due to complications), patients who underwent early surgery had a longer clinical remission ${ }^{19}$. However, the reoperation rate was the same. In this cohort, there was no statistically significant difference between the two groups of patients regarding surgical recurrence. The most common indication for surgery in the emergency surgery group was laparotomy for suspected inflammatory acute abdomen, followed by bowel obstruction, whereas in patients undergoing elective surgery, the main indication was intestinal obstruction, followed by clinical intractability.

The perianal disease affects about 33\% of patients with CD in ten years of evolution and has high morbidity due mainly to pain and drainage in the area, which can lead to complications such as dermatitis, itching, among others ${ }^{10}$. We observed perianal involvement in $26.4 \%$ of patients. In a recent study, Eglinton et al. reported prevalence of symptomatic perianal disease in $26.6 \%$ of patients with $D C^{10}$, much like the rate found in our cohort. In this, the most frequent type of injury was the perianal fistula, followed by abscess, fissure, plicoma and stenosis. The goal of treatment of perianal disease should be aimed to improve the quality of life and is determined by the complexity of involvement. Simple abscesses may be drained, always as close to the anal verge as possible. Simple fistulas can be treated by fistulotomy, as occurred in 12 patients in this study. The seton placement is indicated by the presence of complex fistula, to drain the perianal sepsis and to prevent the sphincter section, which can lead to fecal incontinence ${ }^{20}$. This technique was used in six patients. It is known that the association of seton with immunobiological therapy provides better results in fistulas healing than each type of therapy alone ${ }^{20}$.

In conclusion, surgical recurrence of Crohn's disease affects a significant portion of patients (29.6\%), usually more than five years after the first intervention. The penetrating behavior, especially in the ileocolic topography, associated with perianal involvement most often lead to recurrence after surgical treatment, confirming the prognostic importance of the Montreal classification.

\title{
R E S U M O
}

\begin{abstract}
Objetivo: avaliar a recorrência da doença de Cröhn e seus possíveis fatores preditores em pacientes submetidos ao tratamento cirúrgico. Métodos: estudo retrospectivo de pacientes com doença de Crohn (DC) submetidos a tratamento cirúrgico entre janeiro de 1992 e janeiro de 2012, em acompanhamento regular no Ambulatório de Intestino Clínico do Hospital das Clínicas da UFMG. Resultados: foram avaliados 125 pacientes, sendo 50,4\% do sexo feminino, com média de idade de 46,12 anos, a maioria (63,2\%) com diagnóstico entre 17 e 40 anos de idade. O íleo terminal foi envolvido em 58,4\%, sendo que o comportamento estenosante foi observado em $44,8 \%$ e o penetrante em $45,6 \%$ dos pacientes. Doença perianal foi observada em $26,4 \%$ dos casos. A média de tempo de acompanhamento foi 152,40 meses. Recorrência cirúrgica foi observada em 29,6\%, com um tempo médio de 68 meses até a segunda operação. Conclusão: a localização ileocólica, o comportamento penetrante e o acometimento perianal (L3B3p) estão associados ao maior risco de recorrência cirúrgica.
\end{abstract}

Descritores: Doença de Crohn. Classificação. Recorrência. Fatores de Risco.

\section{REFERENCES}

1. Freeman HJ. Long-term natural history of Crohn's disease. World J Gastroenterol. 2009;15(11):1315-8.

2. Silverberg MS, Satsangi J, Ahmad T, Arnott ID, Bernstein CN, Brant SR, et al. Toward an integrated clinical, molecular and serological classification of inflammatory bowel disease: report of a Working Party of the 2005 Montreal World Congress of Gastroenterology. Can J Gastroenterol. 2005;19 Suppl A:5-36A.

3. Yamamoto T. Factors affecting recurrence after surgery for Crohn's disease. World J Gastroenterol. 2005;11(26):3971-9.

4. Swoger JM, Regueiro M. Evaluation for postoperative recurrence of Crohn disease. Gastroenterol Clin North Am. 2012;41(2):303 14.
5. Albuquerque IC, Carvalho RB, Lopes JM, Pincinato AL, Monteiro EP, Formiga GJS. Doença de Crohn: fatores de risco para recidiva no pós-operatório. Rev bras colo-proctol. 2008;28(1):36-9.

6. Freeman HJ. Application of the Montreal classification for Crohn's disease to a single clinician database of 1015 patients. Can J Gastroenterol. 2007;21(6):363-6.

7. Magro F, Portela F, Lago P, Ramos de Deus J, Vieira A, Peixe P, et al. Crohn's disease in a southern European country: Montreal classification and clinical activity. Inflamm Bowel Dis. 2009;15(9):1343-50.

8. Walfish A, Sachar D. Phenotype classification in IBD: Is there an impact on therapy? Inflamm Bowel Dis. 2007;13(12):1573-5.

9. Oostenbrug LE, van Dullemen HM, te Meerman GJ, Jansen PL, Kleibeuker JH. Clinical outcome of Crohn's disease according to 
the Vienna classification: disease location is a useful predictor of disease course. Eur J Gastroenterol Hepatol. 2006;18(3):255-61.

10. Eglinton TW, Barclay ML, Gearry RB, Frizelle FA. The spectrum of perianal Crohn's disease in a population-based cohort. Dis Colon Rectum. 2012;55(7):773-7.

11. Gasche C, Scholmerich J, Brynskov J, D'Haens G, Hanauer SB, Irvine EJ, et al. A simple classification of Crohn's disease: report of the Working Party for the World Congresses of Gastroenterology, Vienna 1998. Inflamm Bowel Dis. 2000;6(1):8-15.

12. Campbell L, Ambe R, Weaver J, Marcus SM, Cagir B. Comparison of conventional and nonconventional strictureplasties in Crohn's disease: a systematic review and meta-analysis. Dis Colon Rectum. 2012;55(6):714-26

13. Hendren SK, Morris AM. Evaluating patients undergoing colorectal surgery to estimate and minimize morbidity and mortality. Surg Clin North Am. 2013;93(1):1-20.

14. Swoger JM, Regueiro M. Preventive therapy in postoperative Crohn's disease. Curr Opin Gastroenterol. 2010;26(4):337-43.

15. Van Assche G, Dignass A, Reinisch W, van der Woude CJ, Sturm A, De Vos $M$, et al. The second European evidence-based Consensus on the diagnosis and management of Crohn's disease: Special situations. J Crohns Colitis. 2010;4(1):63-101.

16. Borowiec AM, Fedorak RN. Predicting, treating and preventing postoperative recurrence of Crohn's disease: the state of the field. Can J Gastroenterol. 2011;25(3):140-6.
17. Radford-Smith GL. What is the importance of appendectomy in the natural history of IBD? Inflamm Bowel Dis. 2008;14 Suppl 2:572-4.

18. Latella G, Cocco A, Angelucci E, Viscido A, Bacci S, Necozione S, et al. Clinical course of Crohn's disease first diagnosed at surgery for acute abdomen. Dig Liver Dis. 2009;41(4):269-76.

19. Fasci Spurio F, Aratari A, Margagnoni G, Doddato MT, Papi C. Early treatment in Crohn's disease: do we have enough evidence to reverse the therapeutic pyramid? J Gastrointestin Liver Dis. 2012;21(1):67-73.

20. Taxonera C, Schwartz DA, García-Olmo D. Emerging treatments for complex perianal fistula in Crohn's disease. World J Gastroenterol. 2009;15(34):4263-72.

Received on 10/07/2014

Accepted for publication 10/08/2014

Conflict of interest: none.

Source of funding: parcial funding of the Conselho Nacional de Desenvolvimento Científico e Tecnológico (CNPq).

Address for correspondence:

Antonio Lacerda Filho

E-mail: alacerdafilho@gmail.com 